\title{
HOT COMPRESSION DEFORMATION BEHAVIOR AND CONSTITUTIVE ANALYSIS OF EXTRUDED MAGNESIUM-BISMUTH ALLOYS
}

\author{
Guoyuan XIONG ${ }^{1}$, Lihua LIU ${ }^{1}$, Wentao ZHU ${ }^{1}$, Shuping HOU $^{2}$, \\ Weimin $\mathrm{ZHAO}^{3}$, Hui $\mathrm{YU}^{3}$, Zhifeng $\mathrm{WANG}^{3, *}$ \\ ${ }^{1}$ CITIC Dicastal Co., Ltd., Qinhuangdao 066011, China \\ ${ }^{2}$ School of Information Engineering, Tianjin University of Commerce, Tianjin 300140, China \\ ${ }^{3}$ Research Institute of Foundry, School of Materials Science and Engineering, Hebei University of Technology, Tianjin \\ 300401, China
}

\begin{abstract}
The isothermal compression experiments of $\mathrm{Mg}$-2Bi alloys were carried out under different temperature and strain rate by Gleeble $3500 D$ thermal simulation test machine. The rheological stress variation law of the $\mathrm{Mg}$-2Bi alloy was analysed under $200-350^{\circ} \mathrm{C}$ and 0.001 $1.0 \mathrm{~s}^{-1}$. The results present that the peak stress enhances and the dynamic recrystallization grain size reduces with the decline of deformation temperature and the improvement of strain rate during isothermal compression of the $\mathrm{Mg}$-2Bi alloy. In addition, the activation energy for alloy deformation is $130.03 \mathrm{~kJ} / \mathrm{mol}$. The softening mechanism of the $\mathrm{Mg}-2 \mathrm{Bi}$ alloy is mainly twin and dynamic recrystallization under a low temperature $\left(200^{\circ} \mathrm{C}\right)$ condition. While at a higher temperature of $350^{\circ} \mathrm{C}$, the softening mechanism changes to single dynamic recrystallization.
\end{abstract}

Keywords: Mg-Bi alloy, hot compression, constitutive equation, microstructure

\section{Introduction}

As the lightest metal structural material at present, magnesium alloys present the advantages of excellent electromagnetic shielding, good thermal conductivity, high specific strength and stiffness, rich resources and easy recycling, which are known as "green metal structural materials in the 21 st century" [1]. With the increasingly severe situation of energy crisis and environmental pollution of the world, more and more attention has been paid to develop lowcost and high-performance magnesium-based light alloys and promote their wide application in civil fields such as auto parts [2].

In recent years, low-cost Mg-Bi-based alloys have been paid more and more attention by researchers because of their great potential in the development of high strength and toughness magnesium alloys, heat-resistant magnesium alloys, high-speed extruded magnesium alloys and biomedical magnesium alloys. $\mathrm{Bi}$ is a typical precipitable strengthening element in $\mathrm{Mg}$, and $\mathrm{Mg}_{3} \mathrm{Bi}_{2}$ phases can be dynamically precipitated in $\mathrm{Mg}$-Bi-based alloy during plastic processing, resulting in precipitation strengthening effect [3]. In addition, the melting point of $\mathrm{Mg}_{3} \mathrm{Bi}_{2}$ is $831^{\circ} \mathrm{C}$, which is comparable to that of magnesium and rare earth in terms of thermal stability [4]. In the early stage, $\mathrm{Bi}$ element was selected by researchers to alloying with $\mathrm{Mg}$-Al-based, $\mathrm{Mg}$-Sibased and Mg-Zn-based commercial magnesium alloys [5-9] to optimize their microstructure and mechanical properties. The aging strengthening behavior of $\mathrm{Mg}-6.41 \mathrm{Bi}-1.3 \mathrm{Zn}$ (wt.\%) alloy was studied by Sasaki et al. [10]. The edge precipitated strengthening phase was found in the alloy, showing better strengthening effect than base plane precipitation. Researchers began to use $\mathrm{Bi}$ as 
the main alloying element to systematically study the characteristics of precipitation behavior [11]. After introducing 6wt.\% Bi into pure $\mathrm{Mg}$, the extruded $\mathrm{Mg}-6 \mathrm{Bi}$ alloy shows a more uniform and finer microstructure, which is significantly finer than that of extruded pure $\mathrm{Mg}$. Moreover, a large amount of nano-sized $\mathrm{Mg}_{3} \mathrm{Bi}_{2}$ phases is dynamically precipitated in $\mathrm{Mg}$-6Bi alloy. On this basis, a series of $\mathrm{Mg}$-Bi-based multicomponent alloys with excellent strength, toughness, and high-speed extrusion properties have been revealed $[12,13]$. However, there is still a lack of studies on the hot workability of Mg-Bi-based alloys.

In current work, the hot workability of $\mathrm{Mg}-\mathrm{Bi}$ alloys was evaluated through thermophysical simulation experiments. The extruded $\mathrm{Mg}-2 \mathrm{Bi}$ alloy was studied, and the isothermal hot compression experiments were performed under four different deformation temperatures $\left(200-350^{\circ} \mathrm{C}\right)$ and four different strain rates $\left(0.001-1.0 \mathrm{~s}^{-1}\right)$. The flow stress-strain curves of the samples under different hot working conditions were detected, and the deformation behaviors during hot deformation were compared and analyzed. Through the fitting and analysis of the data, the required thermophysical constants of the material can also be obtained, and its constitutive equation can be constructed to provide reference for future work. Furthermore, combined with the results of microstructure evolution, its further hot workability can be comprehensively evaluated to provide reference for the next step of plastic deformation.

\section{Materials and Methods}

The nominal chemical composition of the experimental alloy is Mg-2wt.\%Bi. The target alloy is melted using $\mathrm{Mg}$ ingot $(99.99 \%)$ and $\mathrm{Bi}$ ingot $(99.9 \%)$ through a crucible resistance furnace (SG-5-10). The melting craft, solid solution conditions and extrusion processes are carried out in accordance with the mature process explored in the previous study [3]. The sample was cut from the as-cast alloy ingot. The content of Bi element in the alloy was detected by inductively coupled plasma spectrometer (ICP, Opfima 7300V), which was close to $1.56 \mathrm{wt} . \%$, revealing a certain extent of melting loss of $\mathrm{Bi}$. The isothermal hot compression test is performed by Gleeble 3500D. The maximum heating/cooling rate, maximum output load and deformation speed are $10000^{\circ} \mathrm{C} \mathrm{s}^{-1}, 10 \mathrm{~T}$ and $1 \mathrm{~m} \mathrm{~s}^{-1}$, respectively. The cylindrical samples $(\Phi 8 \mathrm{~mm} \times 12 \mathrm{~mm})$ were used for the isothermal hot compression testing. The strain rates are 0.001, 0.01, 0.1 and 1 $\mathrm{s}^{-1}$, respectively. At each strain rate, four different experimental temperatures $(200,250,300$ and $350^{\circ} \mathrm{C}$ ) were performed. The compression test stops when the true strain reaches 0.8 or when the fracture occurs. The extruded and hot compressed samples for microstructure observation were cut from the center of the sample and polished with sandpaper with different mesh numbers from 40 to $300 \mu \mathrm{m}$, and then polished with diamond suspensions with particle sizes of 3,1 and $0.5 \mu \mathrm{m}$, respectively. A mixed solution $(70 \mathrm{ml}$ ethanol, $10 \mathrm{ml}$ acetic acid, $4.2 \mathrm{~g}$ picric acid, and $10 \mathrm{ml}$ distilled water) was prepared to etch the specimen. After corrosion, optical microscope (OM, OLYCIA M3) was utilized to reveal the microstructure.

\section{Results and Discussion}

\section{Characteristics of true stress-true strain curve}

The true stress-true strain curves of extruded Mg-2Bi specimens during isothermal hot compression at different strain rates and temperatures are uncovered in Fig. 1. The curves obtained under 16 different kinds of process conditions possess similar curve shape. While the flow stress of different samples firstly increases with the improvement in strain. After reaching the peak value rapidly, it begins to decrease slowly and gradually tend to steady flow. When the deformation temperature is $200^{\circ} \mathrm{C}$ and the strain rate is $0.001 \mathrm{~s}^{-1}$, the curve shows a single peak, which is in accord with the typical characteristic of a true stress-true strain curve, indicating that the microstructural evolution of the $\mathrm{Mg}-2 \mathrm{Bi}$ alloy during hot deformation follows the principle 
of discontinuous dynamic recrystallization [14]. Before the arrival of the peak stress, the true stress enhances rapidly with the addition of strain. In this stage, the work-hardening effect of isothermal hot compression on the alloy is generally greater than the softening effect of the internal structural evolution caused by dynamic recrystallization and dynamic recovery [15-17]. It is generally believed that the mechanisms of recrystallization and recovery have occurred in the alloy before the true stress peak appears. With the gradual improvement in softening effect, the increasing rate of softening effect becomes equal to the increasing rate of work hardening. In this situation, the peak value of stress occurs. Subsequently, the effect of the softening mechanism continues to increase, and the stress begins to reduce from the peak value. When the microstructural softening effect and the work hardening effect are equivalent, the flow stress changes into a steady flow state, indicating that the deformation resistance of the material remains unchanged in this stage.
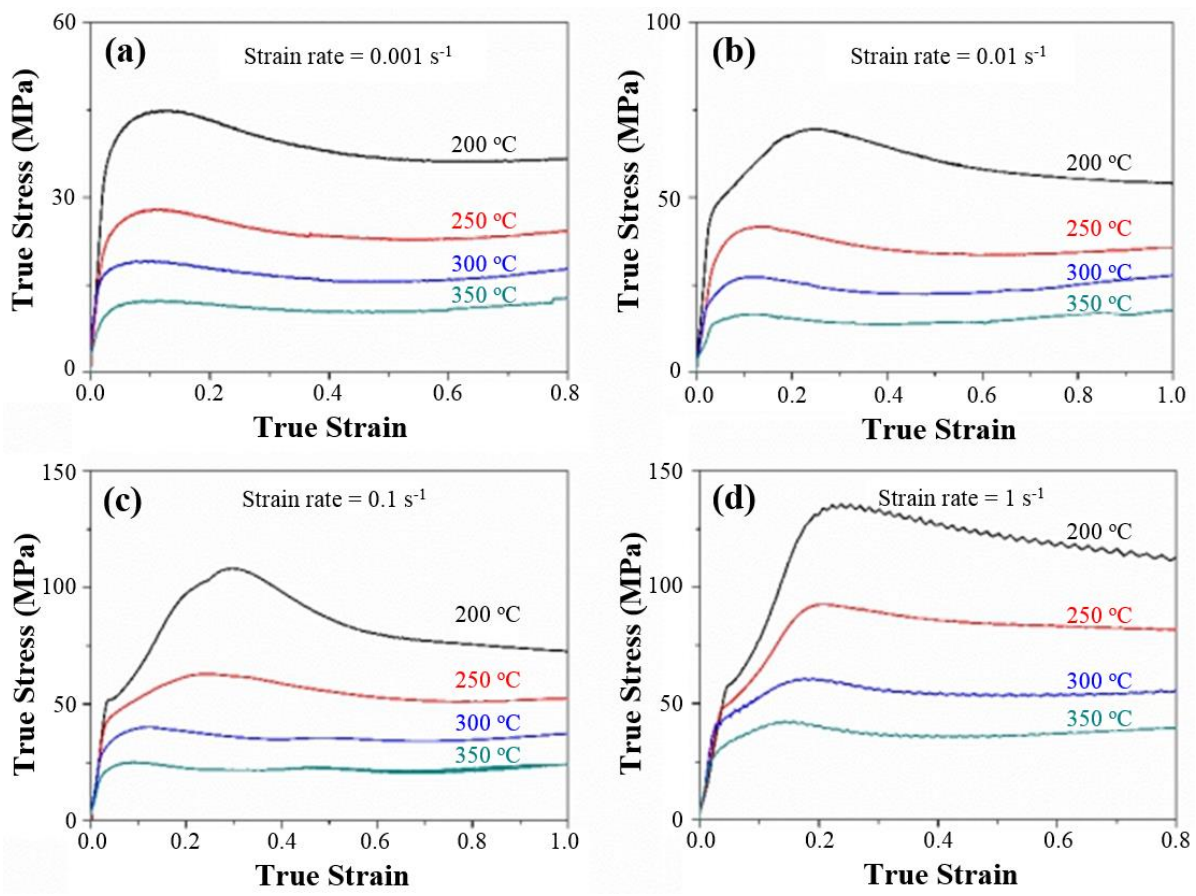

Fig. 1. True stress-true strain curves of extruded $\mathrm{Mg}-2 \mathrm{Bi}$ alloys at different strain rates and temperatures: (a) $\dot{\varepsilon}=0.001 \mathrm{~s}^{-1}$; (b) $\dot{\varepsilon}=0.01 \mathrm{~s}^{-1}$; (c) $\dot{\varepsilon}=0.1 \mathrm{~s}^{-1}$; (d) $\dot{\varepsilon}=1 \mathrm{~s}^{-1}$

When the isothermal hot compression carried out under strain rates at $0.001 \sim 1 \mathrm{~s}^{-1}$, the true stress of extruded $\mathrm{Mg}-2 \mathrm{Bi}$ alloy declines with the improvement in temperature. Within the same isothermal temperature, the true stress increases with the addition of strain rate. As disclosed in Fig. 1a and b, when the strain rate boosts from 0.001 to $0.01 \mathrm{~s}^{-1}$ at $200^{\circ} \mathrm{C}$, the peak stress enhances from 44.8 to $69.61 \mathrm{MPa}$, while the strain hardening stage of the $\mathrm{Mg}-2 \mathrm{Bi}$ alloy becomes longer. It can be seen that during isothermal hot compression process, the work hardening in the $\mathrm{Mg}-2 \mathrm{Bi}$ alloy is in competition with the softening, which is dominated by microstructure evolution, such as recrystallization. The stacking fault energy of most magnesium alloys is low, as a result, dynamic recrystallization tends to occur during hot deformation for most magnesium alloys, which further leads to material softening during deformation. Based on the shape characteristics of true stress-true strain curves obtained by isothermal hot compression toward extruded $\mathrm{Mg}-2 \mathrm{Bi}$ alloy, a deduction can be obtained that discontinuous dynamic recrystallization becomes the 
major mechanism for the microstructure evolution (exerting a softening effect) of the alloy during hot working under the experimental conditions $[18,19]$. It should be noted that when the strain rate reaches to $1 \mathrm{~s}^{-1}$ (Fig. 1d), the true stress-true strain curve of extruded $\mathrm{Mg}$-2Bi alloy presents a wavy shape, which further reveals that the discontinuous dynamic recrystallization mechanism is the primary mechanism for softening the $\mathrm{Mg}-2 \mathrm{Bi}$ alloy under current conditions [20].

When plastic deformation is carried out at a higher deformation temperature and a lower strain rate (Fig. 1), the flow stress basically tends to a steady flow after reaching the peak value. This characteristic indicates that the work hardening and dynamic recrystallization softening effect of the $\mathrm{Mg}-2 \mathrm{Bi}$ alloy almost reach equilibrium at the peak stress. As revealed in Fig. 1b, when the strain rate is $0.01 \mathrm{~s}^{-1}$, under a relatively high temperature, the deformation activation energy is approximately equivalent to the volume diffusion energy of the alloy. Therefore, as the deformation process goes on, the increasing number of dislocations can induce the climbing of abundant dislocations and the generation of subgrains. Meanwhile, the process of dynamic recrystallization is further promoted by the rotation and merging of subgrains. Furthermore, the improvement in temperature also increases the thermal mobility of atoms in the material. In this case, a part of the slip system may be activated due to the reduction of the critical shear stress, which leads to the decrease of the deformation resistance of the alloy. As a result, the peak stress moves forward with the raise of temperature.

\section{Microstructural evolution}

To further study and verify the microstructure evolution of the $\mathrm{Mg}-2 \mathrm{Bi}$ sample after isothermal hot compression deformation with different process conditions, the microstructures of the $\mathrm{Mg}-2 \mathrm{Bi}$ alloys were detected. Fig. 2 displays the optical microstructures of the $\mathrm{Mg}-2 \mathrm{Bi}$ alloys after isothermal hot compression at $200{ }^{\circ} \mathrm{C}$ under strain rates of $0.001 \mathrm{~s}^{-1}$ and $1 \mathrm{~s}^{-1}$, respectively. No cracking occurs during the isothermal hot compression. Under a low temperature and a high strain rate condition $\left(\mathrm{T}=200^{\circ} \mathrm{C}, \dot{\varepsilon}=1 \mathrm{~s}^{-1}\right.$ ) (Fig. 2a and b), a mass of twins form in the alloy after isothermal hot compression. At the same time, it can also be found that the dynamic recrystallization grains have formed, playing a softening effect, which is in accord with the true stress-true strain curve reported above. At a low temperature and a low strain rate condition $(\mathrm{T}=$ $200{ }^{\circ} \mathrm{C}, \dot{\varepsilon}=0.001 \mathrm{~s}^{-1}$ ) (Fig. 2c and d), twins still exist in the microstructure after isothermal hot compression process. However, the volume fraction of twins is significantly reduced, and the proportion of dynamic recrystallized microstructure is obviously increased. At the same time, these recrystallized grains do not appear in the twin boundary or twin interior, indicating that the two types of microstructure evolution are relatively independent during the isothermal hot compression process, and no obvious twins induced dynamic recrystallization phenomenon can be found.

Microstructures of extruded $\mathrm{Mg}-2 \mathrm{Bi}$ alloys processed by isothermal hot compression at $350{ }^{\circ} \mathrm{C}$ and different strain rates from 0.001 to $1 \mathrm{~s}^{-1}$ are displayed in Fig. 3. Different from the relatively low temperature $\left(200^{\circ} \mathrm{C}\right)$, there are no twins in all the $350^{\circ} \mathrm{C}$ hot compressed alloys. In addition, the recrystallization fraction of the alloy is obviously increased. With the addition in strain rate, the unrecrystallized area in the alloy increases gradually, and the recrystallized grain microstructure is slightly refined.

Among the study towards the effect of hot working process on the microstructural evolution, Zener and Hollomon [21] found, through a large number of theoretical integration and experimental studies, that the strain rate $(\dot{\varepsilon})$ and deformation temperature $(\mathrm{T})$, which present significant influences on flow stress $(\sigma)$ during the hot deformation process, can be integrated as the temperatures-compensated strain rate factor. That is, Zener-Hollomon ( $Z$ parameter) is used to describe the relations. The $\mathrm{Z}$ parameter under all stress states is expressed in Equation 1:

$$
Z=\dot{\varepsilon} \exp \left(\frac{Q}{R T}\right)
$$


where R, T, Q and $\dot{\varepsilon}$ represents the gas constant, deformation temperature, deformation activation energy and strain rate, respectively. In general, with the increase of $\mathrm{Z}$ parameter value, the recrystallization fraction in the microstructure decreases, and the recrystallization grain size decreases. It can be seen from Equation 1 that $\mathrm{Z}$ parameter reduces with the improvement of hot compression temperature and the decline in strain rate. In this study, the evolution law of the fraction of recrystallized microstructure and the size change of recrystallized grain of extruded $\mathrm{Mg}-2 \mathrm{Bi}$ alloy at $350^{\circ} \mathrm{C}$ and different strain rates are consistent with the general evolution law of $\mathrm{Z}$ parameter towards microstructure during hot working.

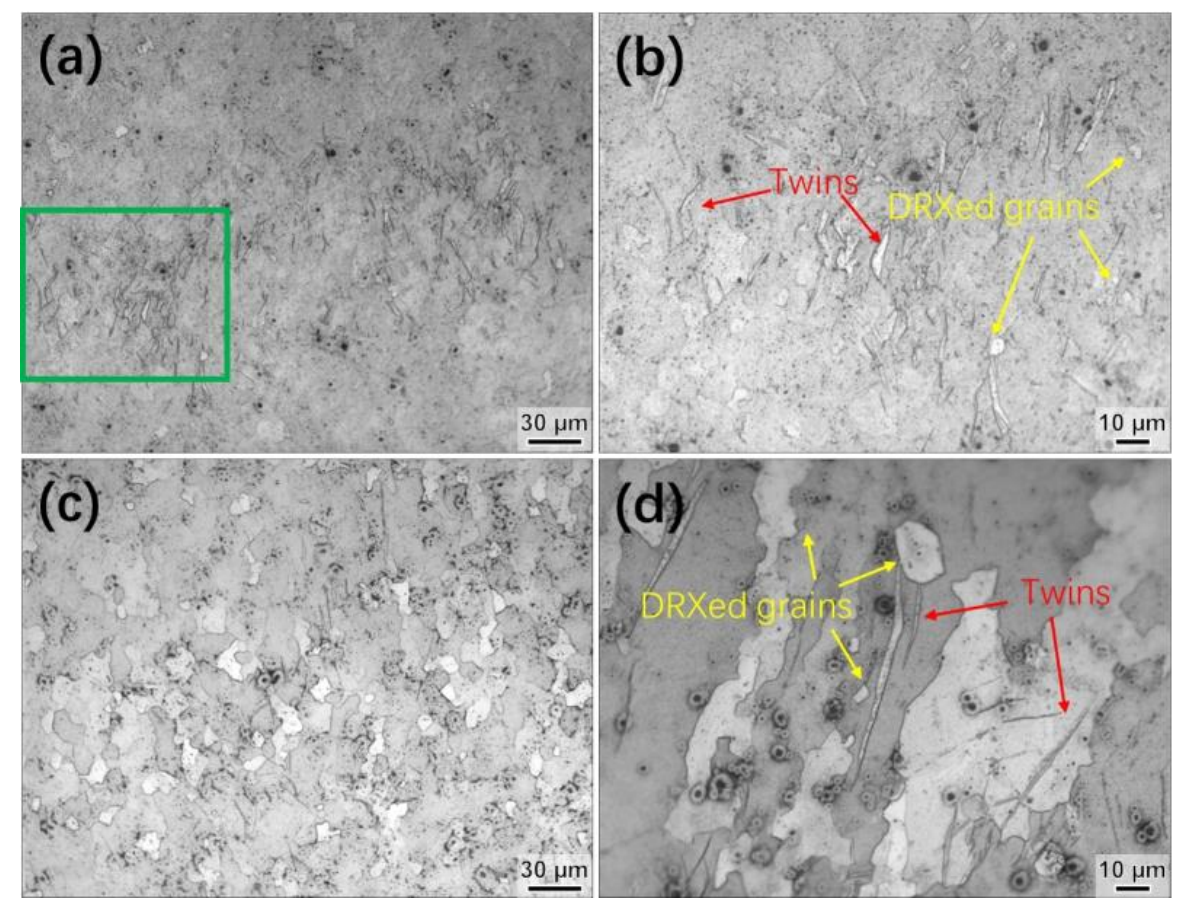

Fig. 2. Optical microstructure of extruded $\mathrm{Mg}-2 \mathrm{Bi}$ alloys after isothermal hot compression: (a, b) $\mathrm{T}=200^{\circ} \mathrm{C}, \dot{\varepsilon}=1 \mathrm{~s}^{-1}$; (c, d) $\mathrm{T}=200^{\circ} \mathrm{C}, \dot{\varepsilon}=0.001 \mathrm{~s}^{-1}$

\section{Construction of constitutive relation}

According to the above data of isothermal hot compression true stress-true strain curve as well as the corresponding analysis and discussion, it is found that the true stress of extruded Mg$2 \mathrm{Bi}$ alloy during isothermal hot compression deformation is in connection with the deformation temperature, strain variable and strain rate. The relationship between flow stress $(\sigma)$ and strain rate $(\dot{\varepsilon})$ of metal materials under different stress conditions can be expressed by power function (low stress conditions) and exponential function (high stress conditions) [22]. Moreover, the relationship between flow stress and strain rate, under the condition of all the stress, can be expressed by the hyperbolic sine function. Therefore, the above three functional relations can be described in Equation 2, 3 and 4, respectively:

$$
\begin{gathered}
\dot{\varepsilon}=A_{1} \sigma_{p}^{n_{1}} \quad(\alpha \sigma<0.8) \\
\dot{\varepsilon}=A_{2} \exp \left(\beta \sigma_{p}\right) \quad(\alpha \sigma>1.2) \\
\dot{\varepsilon}=A\left[\sinh \left(\alpha \sigma_{p}\right)\right]^{n} \exp \left(-\frac{Q}{R T}\right) \quad(\text { for all } \sigma)
\end{gathered}
$$



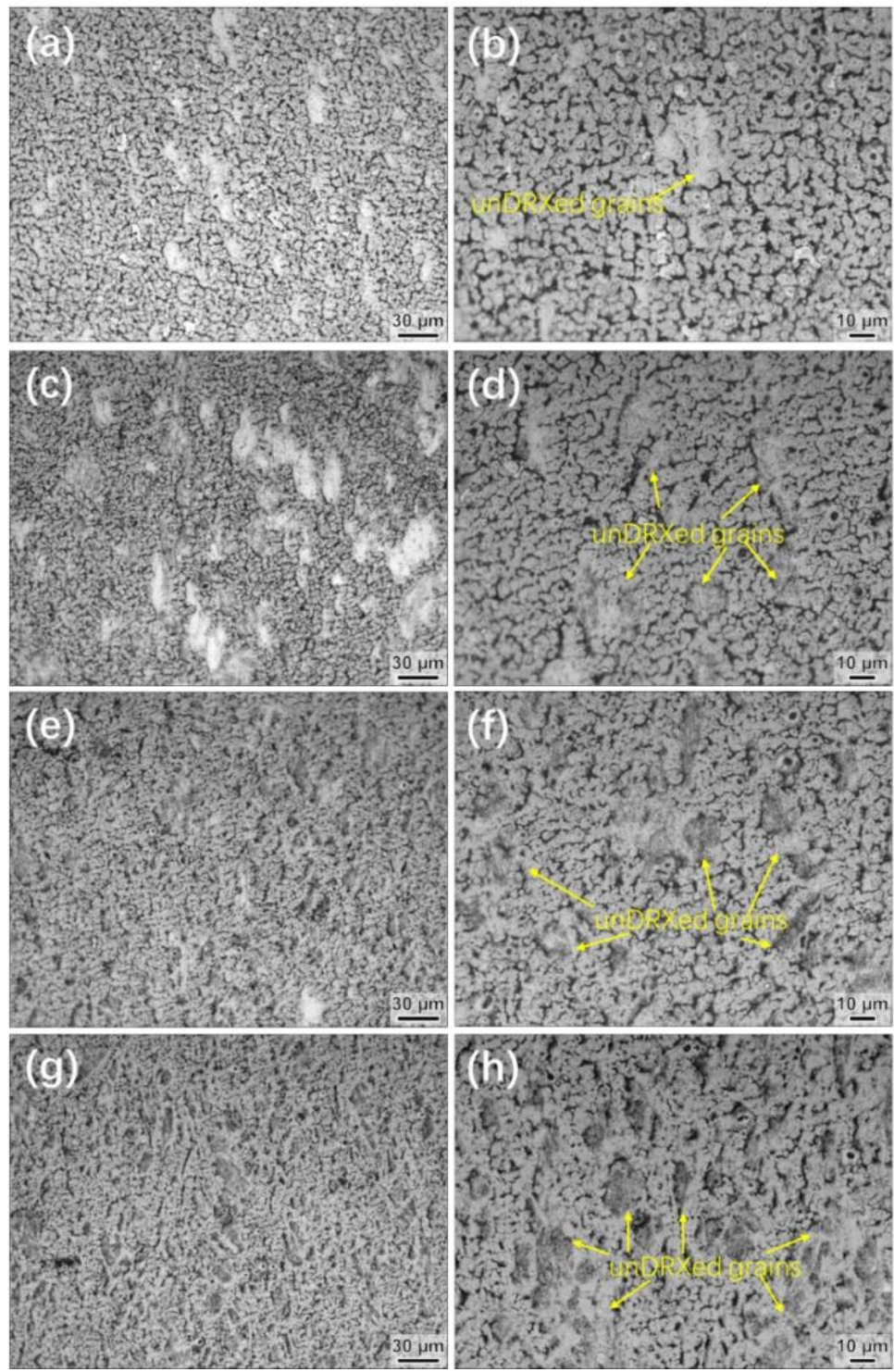

Fig. 3. Optical microstructure of extruded $\mathrm{Mg}-2 \mathrm{Bi}$ alloy after isothermal hot compression:

(a, b) $\mathrm{T}=350^{\circ} \mathrm{C}, \dot{\varepsilon}=0.001 \mathrm{~s}^{-1} ;$ (c, d) $\mathrm{T}=350^{\circ} \mathrm{C}, \dot{\varepsilon}=0.01 \mathrm{~s}^{-1}$; (e, f) $\mathrm{T}=350^{\circ} \mathrm{C}, \dot{\varepsilon}=0.1 \mathrm{~s}^{-1}$; (g, h) T $=350^{\circ} \mathrm{C}, \dot{\varepsilon}=1 \mathrm{~s}^{-1}$.

Through transformation, the following unified Equation 5 can be obtained to express the relationship among different parameters, which is described separately by Equation 2, 3 and 4, respectively:

$$
F^{(\sigma)}= \begin{cases}\dot{\varepsilon}=A F^{(\sigma) \exp \left(-\frac{Q}{R T}\right)} \\ \sigma_{p}^{n_{1}} & (\alpha \sigma<0.8) \\ \exp \left(\beta \sigma_{p}\right) & (\alpha \sigma>1.2) \\ {\left[\sinh \left(\alpha \sigma_{p}\right)\right]^{n}} & (\text { for all } \sigma)\end{cases}
$$


In the above function expressions, the units of strain rate $\dot{\varepsilon}$ is s ${ }^{-1}$. While $A, A_{1}, A_{2}, n_{1}, \alpha$ and $\beta$ are all constants relative to the $\mathrm{Mg}-2 \mathrm{Bi}$ alloy, which can be fitted according to the experimental data and then through the correlated equation. Furtheromre, $\alpha=\beta / n_{1}$, R represents the gas constant $(8.314 \mathrm{~J} / \mathrm{mol} \cdot \mathrm{K})$. The units of deformation temperature $\mathrm{T}$, activation energy $\mathrm{Q}$, and flow stress $\sigma$ at a given strain are $\mathrm{K}, \mathrm{kJ} / \mathrm{mol}$ and $\mathrm{MPa}$, respectively. Because the hyperbolic sine relation model can be utilized to express the relationship among flow stress, strain rate and deformation temperature in the whole stress range (including high stress condition and low stress condition). Therefore, in this study, the hyperbolic sinusoidal model is selected to establish the constitutive equation of extruded $\mathrm{Mg}$-2Bi alloys during isothermal hot compression deformation.

In addition, combined with the hyperbolic sinusoidal model (Equation 4), the expression of $\mathrm{Z}$ parameter in all stress states (Equation 1) is transformed into Equation 6:

$$
Z=\dot{\varepsilon} \exp \left(\frac{Q}{R T}\right)=A\left[\sinh \left(\alpha \sigma_{p}\right)\right]^{n}
$$

The rules of steady-state stress and peak stress in the true stress-true strain curve of magnesium alloys during isothermal hot compression deformation are similar. Therefore, peak stress $\left(\sigma_{\mathrm{p}}\right)$ can be utilized to express the stress-strain curves of the extruded Mg-2Bi alloy with typical peak value. In terms of the true stress-true strain curve, the relation between $\ln \dot{\varepsilon}$ and $\ln \sigma_{\mathrm{p}}$, and between $\ln \dot{\varepsilon}$ and $\sigma_{\mathrm{p}}$ are presented in Fig. $4 \mathrm{a}$ and b, respectively. The least square method is adopted to carry out linear regression processing on the obtained data points. As presented in Fig. 4a and b, good linear relationship can be found between $\ln \dot{\varepsilon}$ and $\ln \sigma_{\mathrm{p}}$ as well as between $\ln \dot{\varepsilon}$ and $\sigma_{\mathrm{p}}$. Combined with the corresponding linear regression analysis results, $\left.\mathrm{n}_{1}=5.622795\right)$ and $\beta=0.08875$ ) can be obtained. Furthermore, the $\alpha$ value is determined according to $\alpha=\beta / \mathrm{n}_{1}$, which is $0.015784 \mathrm{MPa}^{-1}$. At a determinate strain rate, the $\mathrm{Q}$ of the $\mathrm{Mg}-2 \mathrm{Bi}$ alloy can be estimated by the following Equation 7:

$$
Q=R\left[\frac{\partial \ln [\sinh (\alpha \sigma)]}{\partial\left(\frac{1}{T}\right)}\right]_{\dot{\varepsilon}}\left[\frac{\partial \ln \dot{\varepsilon}}{\partial \ln [\sinh (\alpha \sigma)]}\right]_{T}
$$

Clear linear relationship between $\ln \left[\sinh \left(\alpha \sigma_{\mathrm{p}}\right)\right]$ and $\ln \dot{\varepsilon}$ as well as between $\ln \left[\sinh \left(\alpha \sigma_{\mathrm{p}}\right)\right]$ and 1/T can be found from Equation 5, according to the transformation of the mathematical equation. The above two groups of data are respectively drawn and fitted, and the curves are shown in Fig. 4c and d, respectively. In addition, the stress index $\mathrm{n}$ can be obtained from Fig. 4c and expressed in Equation 8:

$$
n=\left[\frac{\partial \ln \dot{\varepsilon}}{\partial \ln [\sinh (\alpha \sigma)]}\right]_{T}=4.50784
$$

Combined with the fitting results of Fig. $4 \mathrm{c}$ and d, the average activation energy of hot deformation can be calculated through Equation 7 as $130.03 \mathrm{~kJ} / \mathrm{mol}$, which is lower than that of ZK60 (140 kJ/mol) and ZKE600 (145.76 kJ/mol) alloys under isothermal hot compression [23]. This is mainly because the role of Bi element in magnesium alloy is different from that of $\mathrm{Zn}$ element in magnesium alloy. For example, they possess big difference in the solute drag effect.

Mathematical processing was carried out on Equation 6. As shown in Fig. 5, after taking the logarithm, $\ln \left[\sinh \left(\alpha \sigma_{\mathrm{p}}\right)\right]$ and $\ln Z$ is conform to a linear relationship. Its slope corresponds to $\mathrm{N}$ value with a magnitude of 4.41 , and its intercept corresponds to $\ln \mathrm{A}$ value with a magnitude of $1.34 \times 10^{11}$. After mathematical processing, the constitutive Equation 9 can be obtained finally:

$$
\dot{\varepsilon}=A^{[\sinh (\alpha \sigma)]^{n} \exp \left(-\frac{Q}{R T}\right)}=1.34 \times 10^{11}[\sinh (0.0158 \sigma)]^{4.41} \exp \left(-\frac{130.03 \times 10^{3}}{R T}\right)
$$



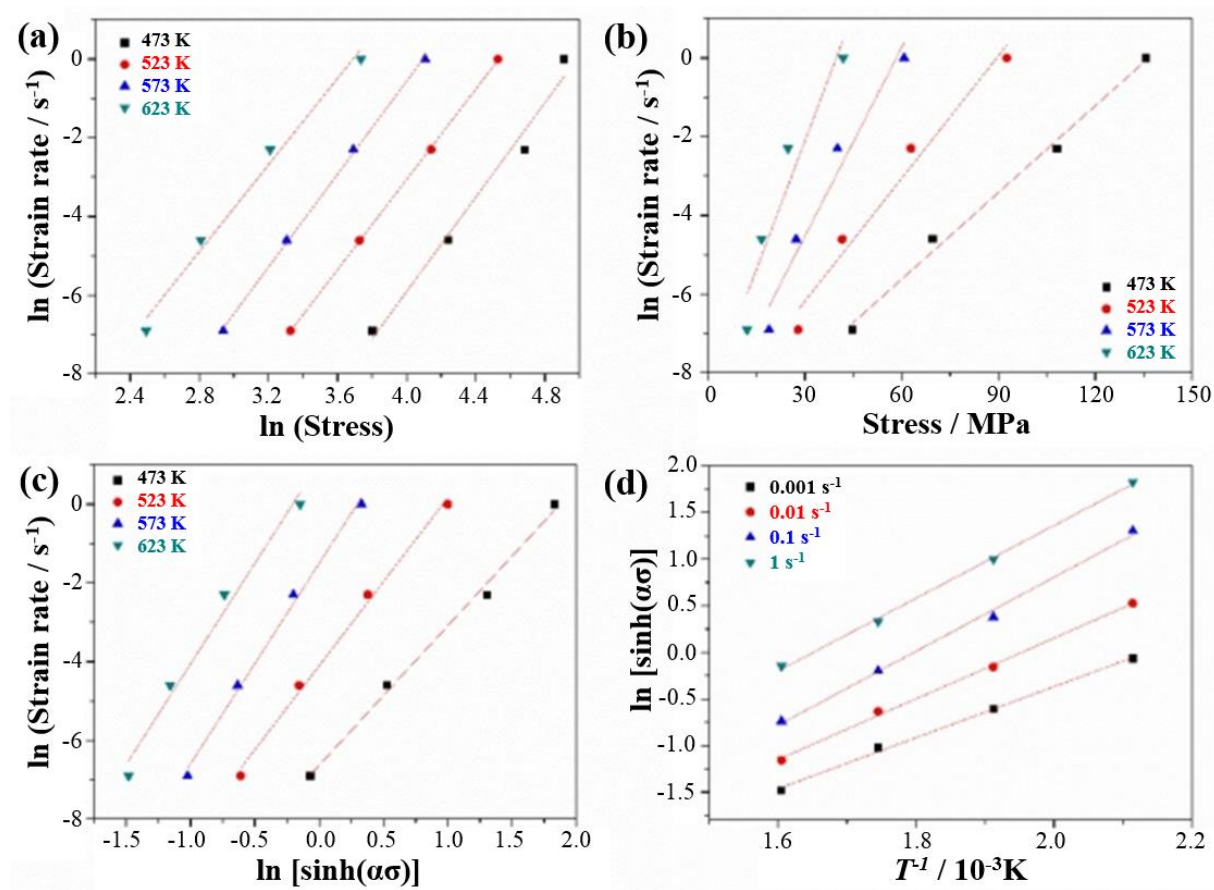

Fig. 4. Relationship among peak flow stress, strain rate and deformation temperature of extruded Mg-2Bi magnesium alloys after isothermal hot compression: the relationship between (a) $\ln \sigma_{\mathrm{p}}$ and $\ln \dot{\varepsilon}$; (b) $\sigma_{\mathrm{p}}$ and $\ln \dot{\varepsilon}$;

(c) $\ln \left[\sinh \left(\alpha \sigma_{\mathrm{p}}\right)\right]$ and $\ln \dot{\varepsilon} ;$ (d) $\ln \left[\sinh \left(\alpha \sigma_{\mathrm{p}}\right)\right]$ and $1 / T$.

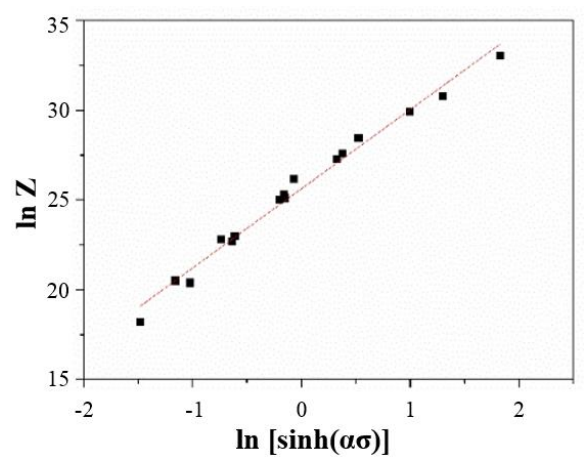

Fig. 5. Relationship between flow stress and Zener - Hollomon parameters

In combination with the definition of hyperbolic sine function, the flow stress expression can also be expressed by the following Equation 10 with parameter Z:

$$
\sigma^{p}=\frac{1}{\alpha} \ln \left\{\left(\frac{Z}{A}\right)^{\frac{1}{n}}+\left[\left(\frac{Z}{A}\right)^{\frac{2}{n}}+1\right]^{\frac{1}{2}}\right\}
$$

The parameters $\alpha=0.015784 \mathrm{MPa}^{-1}, \mathrm{Z}=\dot{\varepsilon} \exp (130030 /(\mathrm{R} \cdot \mathrm{T})), \mathrm{A}=1.34 \times 10^{11}, \mathrm{n}=4.41$ obtained by numerical fitting were substituted into Equation 10. As a result, the functional 
relationship among flow stress, deformation temperature, strain and strain rate can be obtained, which reveals the constitutive relation of hot working of the extruded $\mathrm{Mg}-2 \mathrm{Bi}$ alloy.

\section{Conclusions}

The hot working behavior of the extruded $\mathrm{Mg}-2 \mathrm{Bi}$ specimens was studied by isothermal thermophysical simulation.

1) The flow stress of extruded $\mathrm{Mg}$-2Bi alloy declines with the improvement in deformation temperature and the reduction of strain rate during isothermal compression.

2) The activation energy of hot deformation towards extruded $\mathrm{Mg}-2 \mathrm{Bi}$ alloy is calculated to be $130.03 \mathrm{~kJ} / \mathrm{mol}$ on account of the hyperbolic sinusoidal constitutive model.

3) The flow stress constitutive equation of hot compression deformation processing towards extruded $\mathrm{Mg}-2 \mathrm{Bi}$ alloy is:

$$
\dot{\varepsilon}=1.34 \times 10^{11}[\sinh (0.0158 \sigma)]^{4.41} \exp \left(-\frac{130.03 \times 10^{3}}{R T}\right)
$$

4) The softening mechanism of the extruded $\mathrm{Mg}$-2Bi alloy is mainly twinning and dynamic recrystallization at a low temperature of $200^{\circ} \mathrm{C}$. While at a higher temperature of $350^{\circ} \mathrm{C}$, the softening mechanism tends to single dynamic recrystallization.

\section{Acknowledgement}

The work was financially supported by the research "Development and Application of Key Preparation Technology of High Strength and Toughness Magnesium Alloys for Automobile Wheel Hub" from Hebei Development and Reform Commission and Hebei Provincial Department of Finance, China.

\section{References:}

[1] S. You, Y. Huang, K.U. Kainer, N. Hort, Recent research and developments on wrought magnesium alloys, Journal of Magnesium and Alloys, 5(3), 2017, pp. 239-253.

[2] S.J. Meng, H. Yu, S.D. Fan, Q.Z. Li, S. H. Park, J. S. Suh, Y. M. Kim, X.L. Nan, M.Z. Bian, F.X. Yin, W.M. Zhao, B. S. You, K. S. Shin, Recent progress and development in extrusion of rare earth free Mg alloys: A review, Acta Metallurgica Sinica (English Letters), 32(2), 2019, pp. 145-168.

[3] S.J. Meng, H. Yu, H.X. Zhang, H.W. Cui, Z.F. Wang, W.M. Zhao, Microstructure and mechanical properties of extruded pure $\mathrm{Mg}$ with Bi addition, Acta Metallurgica Sinica, 52(7), 2016, pp. 811-820.

[4] D.W. Zhou, J.S. Liu, S.H. Xu, P. Peng, Thermal stability and elastic properties of $\mathrm{Mg}_{3} \mathrm{Sb}_{2}$ and $\mathrm{Mg}_{3} \mathrm{Bi}_{2}$ phases from first-principles calculations, Physica B, 405, 2010, pp. 2863-2868.

[5] G.Y. Yuan, Y.S. Sun, W.J. Ding, Effects of bismuth and antimony additions on the microstructure and mechanical properties of AZ91 magnesium alloy, Materials Science and Engineering: A, 308, 2001, pp. 38-44.

[6] Y.X. Wang, J.X. Zhou, J. Wang, T.J. Luo, Y.S. Yang, Effect of Bi addition on microstructures and mechanical properties of AZ80 magnesium alloy, Transactions of Nonferrous Metals Society of China, 21(4), 2011, pp. 711-716.

[7] S.W. You, I.H. Kim, Solid-state synthesis and thermoelectric properties of Bi-doped $\mathrm{Mg}_{2} \mathrm{Si}$ compounds, Current Applied Physics, 11(3), 2011, pp. S392-S395. 
[8] C. He, C.Q. Liu, H.W. Chen, J.F. Nie, Enhanced age-hardening response in Mg-Zn-Co alloys with Bi additions, Journal of Alloys and Compounds, 815, 2020, pp. 15-27.

[9] Z.H. Huang, W.H.B. Liu, W.J. Qi, J. Xu, N. Zhou, Effects of Bi on the microstructure and mechanical property of ZK60 alloy, Journal of Magnesium and Alloys, 3(1), 2015, pp. 29-35.

[10] T.T. Sasaki, T. Ohkubo, K. Hono. Precipitation hardenable Mg-Bi-Zn alloys with prismatic plate precipitates, Scripta Materialia, 61(1), 2009, pp. 72-75.

[11] Y.H. Sun, B.Z. Sun, Investigation of structure, morphology and orientation of precipitates in Mg-Bi alloy, Materials Characterization, 140(10), 2018, pp. 129-133.

[12] S. Meng, H. Yu, H. Zhang, H. Cui, S. H. Park, W. Zhao, B. S. You, Microstructure and mechanical properties of an extruded Mg-8Bi-1Al-1Zn (wt.\%) alloy, Materials Science and Engineering: A, 690, 2017, pp. 80-87.

[13] S.J. Meng, H. Yu, H.W. Cui, J. Zhang, W.M. Zhao, Z.F. Wang, C.L. Qin, Microstructure and mechanical properties of new Mg-Bi-Al-Zn wrought magnesium alloy, The Chinese Journal of Nonferrous Metals, 27(5), 2017, pp. 894-901.

[14]K. Huang, R.E. Logé, A review of dynamic recrystallization phenomena in metallic materials, Materials \& Design, 111(10), 2016, pp. 548-574.

[15] Y.B. He, Q.L. Pan, Q. Chen, Z.Y. Zhang, X.Y. Liu, W.B. Li, Modeling of strain hardening and dynamic recrystallization of ZK60 magnesium alloy during hot deformation, Transactions of Nonferrous Metals Society of China, 22(2), 2012, pp. 246-254.

[16] A. Hadadzadeh, M.A. Wells, S.K. Shaha, H. Jahed, B.W. Williams, Role of compression direction on recrystallization behavior and texture evolution during hot deformation of extruded ZK60 magnesium alloy, Journal of Alloys and Compounds, 702(10), 2017, pp. 274-289.

[17] Z. Su, L. Wan, C.Y. Sun, Y. Cui, D.J. Yang, Hot deformation behavior of AZ80 magnesium alloy towards optimization of its hot workability, Materials Characterization, 122(10), 2016, pp. 90-97.

[18] G. Jagan Reddy, N. Srinivasan, A.A. Gokhale, B.P. Kashyap, Processing map for hot working of spray formed and hot isostatically pressed Al-Li alloy (UL4O), Journal of Materials Processing Technology, 209, 2009, pp. 5964-5972.

[19] A.G. Beer, M.R. Barnett, Microstructural development during hot working of $\mathrm{Mg}-3 \mathrm{Al}-1 \mathrm{Zn}$, Metallurgical and Materials Transactions A, 38(8), 2007, pp. 1856-1867.

[20] A. Galiyev, R. Kaibyshev, G. Gottstein, Correlation of plastic deformation and dynamic recrystallization in magnesium alloy ZK60, Acta Materialia, 49(7), 2001, pp. 1199-1207.

[21] C. Zener, J. Hollomon, Effect of strain rate upon plastic flow of steel, Journal of Applied Physics, 15(10), 1944, pp. 22-32.

[22] H.J. McQueen, N.D. Ryan, Constitutive analysis in hot working, Materials Science and Engineering: A, 322(1-2), 2002, pp. 43-63.

[23] H. Yu, Y.M. Kim, H.S. Yu, B.S. You, G.H. Min, Hot deformation behavior and hot workability of Mg-Zn-Zr-Ce alloy, Acta Metallurgica Sinica, 48(9), 2012, pp. 1123-1131. 